HOM E N G EM DE V I A

\title{
Homenagem a Saramago (ou de flores, pessoas e palavras)
}

Mauro Luis lasi*

Joana Carda traçou uma linha no chão com sua vara de negrilho, os cães de Cerbère, que nunca ladram, ladraram ao fundo, enquanto os estorninhos passaram a seguir o pobre José Anaiço, ao mesmo tempo que Joaquim Sassa lançava uma pedra ao mar e a terra tremia sob os pés incrédulos de Pedro Orce... ${ }^{1}$ pronto... a Península Ibérica se soltou do continente europeu e navegou pelo oceano tenebroso da mesma forma que muito tempo antes navegantes portugueses se lançavam com suas naus, sextantes e velas em busca de um novo mundo, ou fugindo do velho mundo que naufragava em terra firme, não se sabe; mas não adiantemos nossa história, pois nada disso seria possível se, em outro momento, numa mera quinta-feira como qualquer outra, pois um dia nada mais é que um dia, ainda que todos os dias, mesmo os mais corriqueiros, tenham sua história e levaria anos para contá-la, mas no mais das vezes não passam mesmo disso, um dia como outro qualquer, e neste em especial nada aconteceu. Nem terra tremeu, nem penínsulas se divorciaram de seus continentes e não fosse o fato de que cães latiram, aliás, como sempre fazem os cães que não são de Cerbère, nada de especial se veria de neste dia, nesta casa, nesta gente humilde que tem casa, mas não tem terra e ainda assim lavra e planta e colhe naquilo que não tem para produzir aquilo que não terá; nesta casa sem terra, neste dia 16 de novembro de 1922 que calhou ser uma quinta-feira, e que não se tire deste fato conclusões, pois poderia ser quarta ou sábado que da mesma maneira

\footnotetext{
* Professor Adjunto da Escola de Serviço Social da UFRJ. Autor de Meta Amor Fase (Expressão Popular, 2008), Ensaios sobre Consciência e Emancipação (Expressão Popular, 2007), O Dilema de Hamlet (Viramundo, 2002), entre outros. Endereço postal: Universidade Federal do Rio de Janeiro, Escola de Serviço Social, Av. Pasteur, 250, fundos, Praia Vermelha, Rio de Janeiro, CEP 22290-240. Email: mauroiasi@hotmail.com

1 Personagens do romance Jangada de pedra (1986), de Saramago.
} 
o rebento nascia, uma vez que não se vem ao mundo munido de calendários, mas por necessidade de sair do ventre e entrar no mundo, sem pedir licença ou saber aonde, se em Portugal ou Espanha, saberá deus onde acaba um e começa outro. Coube ao destino que fora em Portugal, mais precisamente em Azinhaga, no conselho de Colegã, na província de Ribatego, onde nada há, mas havia uma casa de camponeses que não tinham terra, mas tiveram um filho e o chamaram de José, condenando-o, sem o saber, a trabalhar como trabalhou o pai do nome e a ver obras serem paridas sem saber se foi ele mesmo que as fez. Para não esquecer de onde veio coloram em seu nome outros nomes para que entre tantos josés ele se encontrasse consigo mesmo e não se confundisse com os outros que como ele trabalhariam no que não tinham, produzindo para não ter; e foi assim que José carregou também o Souza de sua mãe e Saramago de seu pai. O Souza seguiu o destino das mulheres de Portugal, de negro e na sombra, lembradas para serem em seguida esquecidas, de forma que o rebento que entrara no mundo naquela quinta-feira do mês de novembro do ano de 1922 ficaria conhecido apenas por José Saramago, hoje reconhecido como nome importante de escritor, mas que naquela quinta-feira não passava de nome de trabalhadores sem terra e que na verdade dizia no nome fabricado de letras a carne da coisa que representa, não como o nome da rosa, coisa de importância outra que arrebata corações tomados por paixões avassaladoras e enfeita mesas sofisticadas de gente de nossa melhor sociedade, ou coisa ainda mais séria que Umberto Eco nos conta, mas não explica; pelo contrário aquele nome dizia respeito à coisa bem mais simples e corriqueira, nada mais que uma pequena florzinha silvestre que brota de escombros — saramago — em minúsculo mesmo, pois flor não merece distinção de gente, ainda que como gente brote em qualquer parte, até mesmo em escombros.

No registro encontrar-se-á o dia 18, mas uma coisa é o dia em que se nasce e outra aquele em que se registra o que nasceu, ora, só o que faltava é não considerar o existente por dois dias, tirar da existência dois dias por coisas burocráticas como registros de nascimento. Nasceu e por dois dias o Estado não o reconheceu, talvez por vingança depois de crescido o nascido também o Estado não reconheceu, mas isso são coisas de comunista que depois veremos como se dão. Naquele momento não era comunista nem cristão, apenas era e assim cresceu e se mudou, porque diferente de flor silvestre que sempre está onde nasce, com gente é diferente, sempre carregando suas raízes fora da terra, levantado do chão, navegam com suas coisas e filhos para cidades grandes e frias que os recebem com indiferença e asco como se o chão que assenta a cidade não fosse também o mesmo chão que abrigava os que antes não tinham terra e na cidade continuam não tendo por profissão. Mas cidades são escombros de outra natureza, feitos dos sonhos daqueles que nelas chegam, e o jovem José em Lisboa também sonhava e estudou no Liceu e no Técnico sem, contudo, poder continuar os estudos, pela maldição do nome se colocou a trabalhar desde cedo, aos 12 anos, como serralheiro, depois mecânico, desenhador e funcionário público de vários afazeres na saúde e previdência social e tanto trabalhou que não seguiu estudando como queria. Não podendo desposar os livros em seu templo universitário, os visitava como amante furtivo na Biblioteca Municipal no Palácio Galveias, na freguesia de Nossa Senhora de Fátima bem de frente à Pra- 
ça de Touros do Campo Pequeno, que fora no século XVII casa de campo, quando ali ainda era campo, da família do ilustre e nobre senhor Marquês de Távora que não receberia em sua casa coisa tão pequena como saramago, gente ou flor, mas que em 1759 perdeu a casa por conta de um processo movido pelo Estado envolvendo escândalo de grande monta ligado à tentativa de assassinato de D. José I, o que mostra que nem todo José carrega a maldição do trabalho, ocupando-se de coisa mais nobre, que é governar reinos, sem contar o próprio José que depois de se tornar santo não mais se ocupou da marcenaria por uma espécie de nepotismo celestial; mas o fato é que Dom Francisco de Távora perdeu sua bela casa que de mão em mão passou até que 1928 por ação da Câmara Municipal de Lisboa foi transformada em biblioteca, que diferente de palácios nobres aceita a qualquer um, seja saído ou não de escombros silvestres. Foi ali que o jovem José navegou novamente para longe só que desta vez sem sair do lugar, nas asas de páginas amareladas, cheirando a ácaro e mofo, se converteu em Ícaro e voou protegendo suas frágeis asas de cera do sol inclemente da realidade no interior das paredes de tal palácio que já foi de marqueses e agora se diz público, onde se explica abrigar um menino de pais agricultores como os pais deles, que estudou e trabalhou e agora só trabalha de onde foge para amar os livros às escondidas.

E amou e de tanto amar também passou a amar gente que como sabemos difere de flores e da mesma forma dos livros, ainda que como eles conte histórias que carregamos não em páginas, mas nos olhos e no corpo e nas palavras que dizemos como nos livros e, da mesma forma que nos livros, às vezes nos vemos melhor que em nós mesmos ou em outro qualquer tipo de espelho, às vezes vemos outras pessoas em que nos vemos e, por um momento, já não sabemos onde acaba ela, onde começa a gente e, em fim, nos apaixonamos. E foi assim com José que encontrou Ilda Reis e com ela se casou no ano que então corria e que era o de 1944. Logo depois a terra tremeria e a culpa não foi ainda de Joana Carda e sua vara, mas de um pintor e seu tambor que varreria o mundo com suas hordas e que, ao contrário de nosso personagem, não amava os livros, mas os queimava. No entanto, mesmo em tempos de barbárie nos quais a humanidade mesma quase vira escombros, nascem flores, ainda mais aquelas que por vocação e nome nascem em escombros, e foi assim que no mesmo ano duas flores nasceram e nenhuma delas era flor: uma na forma de gente, também pequena flor silvestre brotando em ruínas, que recebeu o nome de Violante, sua filha; e outra, um pouco flor, um pouco filha, na forma de livro que batizou (porque livros também têm nomes) como o nome de $A$ viúva (1947). Nomes são coisas interessantes, uns ficam com a gente a vida toda, mas por vezes colam em nós nomes que não são nossos e ficam sendo mais nossos nomes que os nomes que nos deram, como aconteceu com Lênin que era Vladimir, e foi isso que se deu com o primeiro livro de nosso escritor que nasceu com o nome de $A$ viúva, mas o editor achou que assim não venderia e o rebatizou de Terra do pecado e desta forma foi conhecido, menos pelo próprio autor que odeia o nome dado, talvez porque tenha sido a primeira vez que se reencontrou com seu destino e de sua família, aquele de produzir coisas que se vão e não mais ficam nossas.

Talvez por isso mesmo, ou porque nasceu com nome de flor silvestre que nasce em escombros, ou por serem seus pais camponeses que não tinham terra 
como seus avós, ou por trazer marcado no corpo a sina daqueles que trabalham para ver seu produto fugir de suas mãos, ou porque se chamava José e tinha que trabalhar e trabalhar, ou porque se parecia a Blimunda, ${ }^{2}$ que quando não comia seu pão pela manhã podia ver dentro das pessoas, ou porque amava as palavras e os livros, e por isso as pessoas, ou porque podia construir na sua cabeça outro mundo que não este no qual flores, pessoas e livros são queimados, ou talvez por tudo isso, se tornou comunista: em 1969 entrou no Partido Comunista Português.

Assim como ninguém nasce cristão ou comunista, um escritor não nasce quando escreve seu primeiro livro. José foi se procurando naquele mar de palavras, mas não se via bem naquilo que escrevia. Seu segundo livro foi rejeitado pelas editoras, chamava-se Claraboia e permaneceu inédito para sempre; só voltaria a publicar dezenove anos depois, mas agora bravo com a prosa resolveu se procurar na poesia e os chamou de Os poemas possíveis (1966). É mais fácil da gente se ver na poesia, ainda que seja mais difícil fazê-la, porque ela se mostra assim inacabada de maneira que uma pessoa olha o que é mostrado e se encontra naquilo que não é revelado, então, ela inventa o resto imaginando que o poeta escreveu para ela. Outros dois livros de poemas viriam, Provavelmente alegria (1970) e O ano de 1993 (escrito em 1975, porque os poemas também não nascem com calendários e às vezes se confundem); tímidos como seu pai/flor silvestre, não se mostraram facilmente a todos que o procuraram e também neles José não se encontrou verdadeiramente. Tinha, pela maldição do nome, que continuar trabalhando, mas foi assim procurando um jeito de ficar perto das amadas palavras e pouco a pouco foi trabalhar em editoras e jornais ${ }^{3}$ e percebeu que as palavras, assim como as flores mudam, ainda que sejam sempre as mesmas flores, não são sempre as mesmas palavras, que plantadas em prosa soam solenes, em poesia se tornam leves como plumas e no jornal se apresentam duras. Como ele amava as palavras incondicionalmente, as amava como elas eram, leves ou densas, alegres ou cínicas, poéticas, sublimes ou duras, como amava as pessoas que da mesma forma assim se apresentam, como flores e palavras, às vezes meigas, às vezes cruéis, portanto, não poderia amá-las menos pela crueza do dia a dia contando-nos coisas prosaicas e corriqueiras, sobre coisas que marcam tão fortemente um dia, mas que raramente são lembradas na semana, nas cinzas do mês ou no túmulo dos anos. Desta forma, pois a vida encontra formas muito várias para promover encontros, uma flor silvestre sem terra, nascida de escombros, que havia encontrado e amado os livros, que por amar palavras, pessoas e flores se tornou comunista, que por querer ser escritor pariu dois romances em que não se viu, que na poesia se procurou sem se achar, encontrou-se com a crônica. Deste encontro foram seus filhos: Deste mundo e do outro (1971), A bagagem do viajante (1973), As opiniões que o DL (Diário de Lisboa) teve (1974), Os apontamentos (1977).

Foi quando estava a trabalhar nos jornais a escrever crônicas, pequenos pedaços da vida tomados pelas palavras, que a vida mesma se virou do avesso em sua Portugal e as palavras e as flores e as gentes tomaram as cidades/escombros de

\footnotetext{
${ }_{2}^{2}$ Personagem do livro de Saramago O memorial do convento (1982).

${ }^{3}$ Saramago trabalhou na Editorial Estudos Cor e nos jornais Diário de Notícias e Diário de Lisboa.
} 
onde nasceram e marcharam nas ruas recolhendo os sonhos daqueles tantos que por elas haviam passado, como pequenas flores que rompem os escombros e buscam o sol e se tornam vivas e se tornam vermelhas e se tornam cravos, que são flores estranhas e belas que se dão para as amadas, se atiram aos toureiros, são mordidas por lábios de irrequietas dançarinas espanholas e ornam túmulos desafiando o fim de tudo com a continuidade sutil da beleza e que ali ornavam fuzis, instrumentos de morte, transformando-os em vasos de flores, porque um fuzil, como as flores, as palavras e as pessoas podem ser muitas coisas além delas mesmas, como um soldado adestrado na arte de matar, que já foi flor pequena em sua aldeia, que já foi gente antes de se tornar engrenagem da máquina de morte pode se transformar novamente em cravos, que podem ser pregos grandes que prenderam Jesus na cruz ou flores belas que tiram o povo dela, e abraçar seu povo que virou uma linda flor vermelha chamada Revolução e que nasceu no dia 25 de abril de 1974: um sábado.

Saramago volta ao Diário de Notícias, agora como seu diretor, veja onde flores pequenas podem chegar levadas pelas pétalas de uma revolução. A vida Ihe parecia agora um livro sendo escrito no qual as palavras reencontram as coisas que as pariram, os poemas, os livros e as crônicas empalidecem diante desta obra coletiva. Mas as revoluções, como a terra e seus produtos, como as flores, os livros e as pessoas, podem fugir de nossas mãos, podem virar livros nos quais não nos reconhecemos mais. Em novembro de 1975, dez meses depois de assumir a direção do Diário, os militares demitem os funcionários acusados de promover os excessos da revolução de abril. Já murcharam sua festa oh pá, mas certamente, esconderam uma semente n'algum canto de jardim. Mas, isso quem disse não foi José, foi Francisco com seus olhos de água clara que cultiva o hábito de guardar lágrimas que não são suas. Saramago reage como um dia, do outro lado do mundo, amaldiçoou Jack London ao dizer: "não vou nunca mais trabalhar como trabalhei e que Deus me fulmine se algum dia eu der de mim mais do que meu corpo pode dar e desde então tenho me dedicado a fugir do trabalho". Nosso amado escritor reagiu de forma mais prudente, talvez por ser ainda flor pequena, talvez por ser português, mas no mesmo sentido ao dizer: "Estava à espera de que as pedras do puzzle do destino - supondo-se que haja destino, não creio que haja - se organizassem. É preciso que cada um de nós ponha a sua própria pedra, e a que eu pus foi esta: Não vou procurar trabalho!" Assim, como amante que se esquece da hora no corpo da amada, nosso José se entregou às palavras para viver nelas e delas viver.

Por falar em amadas, quase nos esquecemos falando de coisas de livros e de revolução, que os amores, como as flores, as palavras e as revoluções, também envelhecem e o dele envelheceu como palavras que por muito tempo não ditas, guardadas em seus túmulos de papel, distantes do carinho da língua, não mais se reconhecem quando encontradas, da mesma forma amores passaram e amores vieram, como Isabel de Nóbrega em 1966. Mas, da mesma forma que nas palavras e nos livros, também nos amores às vezes não nos encontramos e seguimos procurando até que ele nos encontra. Foi assim, um pouco pelos livros, um pouco pelos encontros, que outra moça que lia o autor que se escondia atrás das palavras que escrevia, conseguiu vê-lo atrás das palavras que o escondiam. Seu nome era Pilar del Rio que procurou o José por trás das palavras de Saramago e dizem que o en- 
controu e ele a ela e assim ficaram, ele nascido em Portugal, ela em Espanha, mas como já se disse, sabe-se lá onde termina um e começa a outra, como eles também se confundiram desde 1986 e assim ficaram sem bem saber onde acabava um e começava a outra.

Tendo se procurado nos romances e nos poemas e nas crônicas e nas revoluções, seguindo seu destino de José, de flor pequena que nasce em escombros, sem se encontrar verdadeiramente em nada embora em tudo se buscando, o português demitido escreveu mais um livro, assim como alguém que não enxergando direito o caminho à frente resolve voltar atrás para ver se consegue se encontrar, e assim nasceu o Levantado do chão (1980), ${ }^{4}$ no qual camponeses do Alentejo lutam por terra desde o século XIX até o 25 de abril de 1974. Sem bem saber se escrevia romances, poemas, crônicas, se mesmo escrevia ou pensava o mundo e assim filosofava, ou se conversava, ou se como seus pais e avós fizeram por toda a vida, plantava sem ter terra, por isso construía sua obra no ar das palavras, Saramago resolveu misturar tudo isso e escrever romances-poemas-crônicas-filóficas, enfim, conversas e como tal sem parágrafo e travessão, sem indicar quem fala e se fala ou só pensa, levam o leitor para dentro de uma trama de tal modo que ele fica sem saber ao certo se lê ou participa, se é ele pensando o que o autor esta escrevendo ou este escrevendo o que ele já pensou ou vai pensar. Não sabemos ao certo de onde veio isto, de Camões ou de Marx, de Azinhaga ou de Lisboa, dos escombros de um Portugal que já foi grande, ou da pequenez de uma flor silvestre, mas, certamente, chegou com o Memorial do Convento (1982), livro que Pilar leu em sua Espanha e não descansou até que achou quem o escreveu, livro que começa com a promessa do Rei de construir um convento caso a rainha engravidasse e acaba envolvendo três personagens: Blimunda, filha de uma herege queimada na fogueira da Inquisição e que tem o poder de ver dentro das pessoas quando não come pela manhã, Baltazar Sete-sois, que perdeu a mão na guerra com a Espanha, e o Frei Bartolomeu Lorenço, que insiste que o homem podia voar fazendo uma máquina que se levanta com o éter das pessoas aprisionados em frascos de âmbar.

Seguiriam O ano da morte de Ricardo Reis (1984), A jangada de pedra (1986), no qual nossa Joana Carda e sua vara de negrilho risca o chão e a península Ibérica, singra os mares, não encontrando lugar nem na Europa de onde partiu, nem no Novo Mundo, onde não chegou; A história do cerco de Lisboa (1989), O Evangelho Segundo Jesus Cristo (1991), Ensaio Sobre a Cegueira (1995), Todos os Nomes (1997), A Caverna (2000), O Homem Duplicado (2002), Ensaio Sobre a Lucidez (2004), As Intermitências da Morte (2005), A Viagem do Elefante (2008) e seu último romance, Caim (2009), além de peças de teatro, contos e livros de viagens.

Como já disse Fernando Pessoa, personagem de $O$ ano da morte de Ricardo Reis, um dos alteregos do poeta, o poeta é um fingidor de tal maneira e tão completamente que chega a fingir que é dor a dor que deveras sente. Saramago em sua prosa falada, ou sua conversa escrita (como nosso Guimarães, que também é flor, só que rosa) nos conduz a uma miríade de personagens tão fantásticos como reais, ${ }^{4}$ Antes dele houve outro que o próprio autor reconhece não ser aquele em que encontra finalmente seu estilo -
Manual de Pintura e caligrafia (1977). 
tão literários quanto corriqueiros, fingindo um mundo fingido que só vemos claramente quando ficamos cegos, como em seu fantástico Ensaio sobre a cegueira. Fechamos os olhos para o mundo e os abrimos para as páginas saramaguianas, e eis que o mundo se nos revela mais fácil de compreender, ainda que cada vez mais difícil de aceitar tal como está, como no dia da eleição na qual ninguém comparece para votar em seu Ensaios sobre a Lucidez, lucidez, aliás, que o povo brasileiro deveria exercitar qualquer dia. Saramago nos parece às vezes que levantava cedo e não comia seu pão para poder olhar para dentro das pessoas como Blimunda, ou sendo o único que vê nos leva a nós cegos pelos caminhos de um mundo em destroços que conhece bem no seu ofício de flor silvestre, de forma que já não sabemos onde acaba o autor onde começam os personagens, como acontece nas paixões e nas revoluções, com Portugal e Espanha, com José e Pilar, com o leitor e o livro.

O leitor só se reconhece na obra em que o autor se reconheceu, assim como o humano no humano, o homem se reconhece primeiro em seu semelhante, disse Marx, ${ }^{5}$ através da relação com o homem José, na condição de seu semelhante, toma o homem Mauro consciência de si mesmo como homem, de forma que é porque o autor se coloca inteiro como ele é na obra que o leitor pode reconhecer naquilo que é o outro, aquilo que ele é. Como um cão velho que trazia como nome Achado, ${ }^{6}$ porque isso mesmo era — achado — , tivesse ele pai para chamá-lo de flor, nome de flor teria, mas como encontrado foi, Achado era seu nome, e que desenvolve a vaga sensação de pertencer a algo maior que ele, como nós a uma classe, um escritor ao seu país, um homem à humanidade. Este velho hábito de nos procurar fora de nós mesmos, em palavras, livros, poemas, pessoas e flores, às vezes também nos leva para longe de nós mesmos em coisas que se voltam contra nós, como nas mercadorias e em deus. Por isso, Saramago viveu buscando o caminho de volta neste estranho fenômeno no qual uma relação entre seres humanos assume a forma fantasmagórica de uma relação entre coisas, como também disse Marx, e fala através de um de seus personagens: "É preciso reconstruir tudo... não tínhamos remédio, quando as coisas éramos nós. Não voltarão os homens a ser postos no lugar das coisas." ${ }^{\prime 7}$ Foi assim que reescreveu o evangelho e nele Jesus era um homem e era filho de um homem que como ele chamava José, que concebeu um filho em sua Maria, que é como os homens fazem quando o espírito santo não está por perto, um filho que tinha medo e tinha dúvidas e errava, como no dia que expulsou os demônios colocando no corpo dos porcos que se jogaram na água e foi perseguido pelos enraivecidos donos dos porcos que perderam seu sustento, ou como quando em um barco reunidos Jesus, o diabo e Deus, o diabo sabendo de tudo que a humanidade iria passar por causa da religião e da morte de Jesus, guerras, cruzadas e inquisições, resolve se render e voltar aos céus submetendo-se à vontade de Deus se isso salvasse o menino e a humanidade de tanto sofrimento, e uma voz acima deles responde: não!

Então, Joana Carda riscou o chão com sua vara de negrilho e separou-se José e seu Portugal, e os cristãos não gostaram de ver Cristo como um homem porque

\footnotetext{
${ }_{5}^{5}$ Marx em O Capital, livro I, volume I, nota 18, página 60, Rio de Janeiro: Civilização Brasileira, s/d.

${ }^{6}$ Personagem canino do romance A Caverna (2000).

${ }^{7}$ Conto As coisas, integrante do livro Objecto quase (1984).
} 
estavam desacostumados a se ver em outras pessoas, acostumados que estavam a ser coisas e a projetar feuerbachianamente o sol da sua existência para alguma coisa fora deles, não gostaram daquilo que leram, mas a culpa não é do livro, como culpado não é o espelho do velho que nos substituiu e das rugas que ele trás.

Saramago navegou uma vez mais, agora para fora de Portugal, exilando-se em sua ilha, em seus livros e no coração de Pilar. Nunca parou de escrever, de amar os livros e as palavras, as flores e as pessoas, nunca parou de pensar, menino pequeno flor silvestre, José condenado ao trabalho, cravo rebelado com os soldados que em um abril ficaram "nus, rodeados pelos homens e pelas mulheres que antes tinham sido roupas e armas", ${ }^{8}$ quando ganhou o prêmio Nobel em 1998, o mesmo Nobel que inventou a dinamite no mesmo ano que Marx publicou o primeiro livro de $O$ capital, que como ele nunca deixou de ser comunista, mesmo sob escombros de muros e estados, acostumado que estava a brotar de escombros, disse: "Eu sou o que poderia se chamar de um comunista hormonal. Da mesma forma que tenho no meu corpo, não sei onde, um hormônio que me faz crescer a barba, há um outro hormônio que me leva, ainda que não queira, a ser comunista." ${ }^{1}$

E Joana Carda riscou o chão mais uma vez.

A terra não tremeu, penínsulas não partiram como jangadas enfrentando o mar tenebroso, os cães de Cerbère não ladraram, nem estorninhos seguiram ninguém. Blimunda que esquecerá de comer seu pão viu um grande vazio dentro das pessoas. Cegos, votantes, Cipriano Algor, oleiro por profissão e sua filha Marta, cães achados e perdidos, Jesus e o diabo, Ricardo Reis, homens duplicados, Baltazar Sete-sois e Frei Bartolomeu Lorenço, nos olham incrédulos de suas casas de papel. Seu pai partia tranquilamente do mundo, em sua jangada de nada para lugar algum, no colo de sua amada, porque as pessoas, como as flores, as palavras e as revoluções também passam, porque tudo flui e tudo segue. Mas, algumas flores, como certas palavras e determinadas pessoas, desenvolvem a arte de ficar, porque foram elas mesmas e se viram nos outros e generosas nos mostraram a nós mesmos e nos deixaram morar em suas palavras como se fosse nossa casa e nossa terra, terra que seus pais nunca tiveram e meus camaradas ainda não têm, mas que um dia teremos, como ele hoje tem, não apenas aquela onde descansa, mas no coração de todos nós, seus personagens. Dizem que em Azinhaga, no conselho de Colegã, na província de Ribatego, na mesma hora uma pequena flor silvestre brotava de um escombro e um cão uivou um ganido tão triste, tão triste que todas as mulheres de Portugal soltaram ao mesmo tempo um suspiro. Saramago morreu escritor, comunista e pequena flor silvestre no dia 18 de julho: um domingo.

Recebido em 27 de setembro de 2010.

Aceito para publicação em 10 de outubro de 2010.

\footnotetext{
${ }^{8}$ Idem, idibem. (SARAMAGO, J. Objecto quase. São Paulo: Cia das Letras, 2005, p. 105.)
}

${ }^{9}$ Entrevista à Folha de São Paulo, 13 de abril de 2010. 